\title{
PRÁTICA PEDAGÓGICA EM EDUCAÇÃO FÍSICA ADAPTADA: RELATO DE EXPERIÊNCIA
}

\author{
Elizângela Fernandes Ferreira, Universidade Federal de São Carlos - UFSCAR, São Carlos, \\ São Paulo - Brasil \\ Dallila Tamara Benfica, Universidade Federal de Viçosa - UFV, Viçosa, Minas Gerais - \\ Brasil \\ Aurora Corrêa Rodrigues, Universidade Federal de Viçosa - UFV, Viçosa, Minas Gerais - \\ Brasil
}

\begin{abstract}
RESUMO
A formação de professores de Educação Física requer um ensino de qualidade, que lhe confira competência na realização de suas atividades educacionais no âmbito escolar. Nessa perspectiva, a disciplina de Prática Pedagógica se constitui uma das formas de abordagem para a construção deste espaço. Esta disciplina tem como objetivo subsidiar os discentes na sistematização dos conhecimentos e favorecer a troca de conhecimentos. Assim este estudo consiste em um relato de experiência de discente da disciplina Prática Pedagógica em Educação Física Adaptada do Curso de Graduação em Educação Física da Universidade Federal de Viçosa, no período de março de 2010 a julho 2010. Inicialmente foi realizada a apresentação e discussão do ementário, objetivos e metodologia da disciplina. Em seguida, discutiu-se a organização e apresentação dos seminários, tendo como sugestão de trabalho cada grupo realizar uma revisão sobre um determinado esporte paraolímpico e ao seu final apresentar um plano de aula referente a este esporte. Dos resultados obtidos percebemos que as aulas teórico-expositivas possibilitaram uma permuta de conhecimentos. Assim foi possível perceber que a disciplina prática pedagógica possibilita a construção do agir, saber e fazer o ensino inclusivo na perspectiva da Educação Física Adaptada.
\end{abstract}

Palavras-Chave: Educação inclusiva; Prática pedagógica, Formação discente; Educação Física.

\section{PEDAGOGICAL PRACTICE IN ADAPTED PHYSICAL EDUCATION: EXPERIENCE REPORT}

\begin{abstract}
The training of teachers of Physical Education requires a quality education that confers competence in carrying out its educational activities in schools. From this perspective, the discipline of pedagogical practice that constitutes a way of approach to the construction of this space. This course aims to subsidize the students in the systematization of knowledge and promote exchange of knowledge. So this study is to report an experience of student discipline Pedagogical Practice in Adapted Physical Education Course Graduate in Physical Education, Federal University of Viçosa, from March 2010 to July 2010. Initially it was held the presentation and discussion of syllabus, objectives and methodology of the discipline.
\end{abstract}

Conexões: revista da Faculdade de Educação Física da UNICAMP, Campinas, v. 10, n. 1, p. 142-152, jan./abr. 2012. ISSN: 1983-9030 
Then discussed the organization and presentation of seminars, with the suggestion of work each group carry out a review of a particular sport and the Paralympic its end present a lesson plan related to this sport. From the results we see that the theoretical-expository allowed an exchange of knowledge. Thus it was possible to see that discipline pedagogical practice enables the construction of the act, learn and make inclusive education from the perspective of Adapted Physical Education.

Key-Words: Inclusive education; Educational practice; Training students; Physical Education

\section{PRÁCTICA PEDAGÓGICA EN EDUCACIÓN FÍSICA ADAPTADA: INFORME DE LA EXPERIENCIA}

\section{RESUMEN}

La formación de profesores de Educación Física requiere una educación de calidad que asignala competencia en la realización de sus actividades educativas en las escuelas. Desde esta perspectiva, la disciplina de práctica pedagógica que constituye una forma de aproximación a la construcción de este espacio. Este curso tiene como objetivo subsidiar a los estudiantes para la sistematización del conocimiento y promover el intercambio de conocimientos. Este estudio describe una experiencia de la práctica pedagógica en la disciplina de los estudiantes de Posgrado en Educacion Física Adaptada Curso de Formación en Educación Física, Universidad Federal de Viçosa, desde marzo de 2010 julio de 2010. Inicialmente se llevó a cabo la presentación y discusión del plan de estudios, objetivos y metodología de la disciplina. Luego se examinó la organización y presentación de seminarios, con le sugerencias del trabajo de cada grupo de llevar a cabo una revisión de un determinado deporte y los Juegos Paralímpicos para presentar un plan de lecciones relacionadas con este deporte. De los resultados podemos ver que la exposición teóricopermitióun intercambio de conocimientos. Por lo tanto, fué posible ver que la práctica de la disciplina pedagógica permite la construcción de actuar, aprender y hacer de la educación inclusiva desde la perspectiva de la Educación Física Adaptada.

Palabras-Clave: Educación inclusiva; La práctica educativa; La formación de estudiantes; Educación física. 


\section{INTRODUÇÃO}

A inclusão incide em uma ação social, com intuito de viabilizar a inserção de indivíduos deficientes ou com necessidades especiais na sociedade, sendo sua finalidade, estes possuírem os mesmos direitos que os demais ${ }^{1}$. O processo emana de uma discussão consistente e longa. Encontram-se registros a partir do século XIV, sobre uma possível educação para indivíduos considerados ineducáveis. O advento da inclusão no Brasil se deparou a partir do século XIX, como fruto do modismo importado pelos Estados Unidos da América (USA), o qual influencia a forma que o movimento vem assumindo no país ${ }^{2}$.

Pesquisas recentes demonstram como o processo de uma educação inclusiva vem sendo estruturada e desenvolvida de forma precária. ${ }^{3,4,2}$ No entanto os meios de produção do conhecimento estão possibilitando o crescimento das discussões e tornando-a cada vez mais presente no ambiente escolar. ${ }^{4,5}$

De acordo com o inciso III da Constituição Federal Brasileira de 1988 e as Leis de Diretrizes e Bases - LDB (Lei n 9.394/96), a Educação Especial é entendida como uma educação complementar, não substituta ao ensino curricular das escolas regulares, sendo considerada uma modalidade de educação escolar, oferecida preferencialmente na rede regular de ensino, para alunos com alguma necessidade especial. ${ }^{4}$

Porém não satisfaz, apenas, que uma proposta se torne lei para que esta seja imediatamente desenvolvida na sociedade. Diversas são as barreiras que impossibilita a aplicação da política de inclusão na prática cotidiana das escolas brasileiras. Entre estas, a principal, é o despreparo dos professores do ensino regular para receber em suas salas de aula, geralmente repletas de alunos com problemas de disciplina e aprendizagem, essa clientela. ${ }^{5,6,7,8}$ Assim a prática pedagógica dos atuais professores está permeada de mitos, provenientes da concepção estabelecida em anos anteriores que a sociedade possui dois tipos de alunado, o "normal "e o "excepcional". ${ }^{6}$ Contudo ela é um dos fatores principais para que aconteça a inclusão no país. Logo, a forma como os profissionais de Educação Física (EF) estão sendo preparados durante sua formação acadêmica, é essencial para o atendimento adequado das pessoas com deficiência nas escolas inclusivas. 
Neste contexto buscamos compreender a importância da disciplina prática pedagógica aplicada a Educação Física Adaptada, pertencente à grade curricular do curso de Educação Física da Universidade Federal de Viçosa (UFV), Minas Gerais, e também formar um posicionamento crítico sobre as metodologias utilizadas pelos docentes e discentes.

\section{PRÁTICA PEDAGóGICA, EDUCAÇ̃̃o INCLUSIVA E EDUCAÇÃo FÍSICA}

A Prática Pedagógica é expressa pelas atividades rotineiras que são desenvolvidas no cenário escolar, podendo ser atividades planejadas com desígnio de viabilizar uma transformação ou podem ser atividades denominadas bancárias, com a dimensão de depósito do conteúdo como característica essencial, sendo ainda influenciada pela cultura social. ${ }^{7}$

Neste contexto, em conjunturas atuais, temos a reflexão de uma prática pedagógica voltada para a Educação Especial, ou seja, uma prática que possa atender indivíduos com necessidades especiais. Direito determinado pela Constituição Brasileira de 1988, ${ }^{8,9}$ assegurados também pela LDB n 9394/96. ${ }^{2}$ Assim efetiva-se o debate na temática exclusão e inclusão, desencadeando um momento de desafios aos professores que se defrontam com o novo e com o diferente na sala de aula.

A discussão da inserção de indivíduos, como deficientes ou que necessitam de necessidades especiais na sociedade, originou-se no campo educacional, em meados da década de 90 com a Educação Inclusiva. Movimento enraizado nos Estados Unidos da América e posteriormente lastrado pelo mundo até mesmo no Brasil, com início no século XIX. ${ }^{2,4}$

A partir deste período as metodologias de ensino dos professores vêm sendo questionadas a respeito da transmissão do conhecimento com intuito de atender a todos. Então pensemos em prática pedagógica, a qual envolve um arranjar ordenado, dependente dos professores e alunos no ambiente da sala de aula. Exigindo um momento de planificação, interação, avaliação e, finalmente, reflexão crítica da ação desenvolvida. ${ }^{9}$

Nesta perspectiva podemos perceber que a disciplina Educação Física escolar torna-se um dos meios para que a inclusão aconteça, pois a atividade motora orientada, levando em consideração as possibilidades dos alunos, viabiliza-o a valorizar e integrar-se à realidade, 
obtendo autonomia, autoconfiança e liberdade de expressão. Contudo, para uma possível Educação Inclusiva, é necessário pensar em uma nova prática escolar.

$\mathrm{Na}$ área da EF, autores como Soares, Varjal, Castelani Filho, Escober e Bracht10 pensam a EF enquanto prática pedagógica, uma fonte de diferentes expressões das atividades corporais. Assim configura-se a área de conhecimento chamada cultura corporal de movimentos. ${ }^{16}$ Assim, são acopladas às aulas, a cultura proveniente de cada aluno, suas experiências e vivências anteriores e, a partir de tal ponto almeja-se a construção de uma prática voltada a atender as necessidades individuais e grupais, respeitando, consequentemente suas dificuldades e peculiaridades. Tal processo permite um ambiente voltado para a aprendizagem, onde professor e aluno ensinam e aprendem mutuamente.

Porém estudos como o de Aguiar e Duarte, ${ }^{11}$ demonstram a dificuldade desse processo de inclusão. Esses autores tiveram como objetivo investigar os significados da inclusão de pessoas com necessidades especiais nas aulas de EF no sistema regular de ensino. Os resultados apontaram que cerca de $97 \%$ dos professores não haviam conhecimentos suficientes para incluir alunos com alguma necessidade especial nas aulas de EF, apesar de acreditarem que a participação deles, nas aulas, poderia auxiliar na sua inclusão escolar.

Para que estes problemas sejam sanados é preciso que haja intervenção governamental. É necessário realizar seminários a respeito deste tema, capacitação de professores de EF por intermédio de cursos, criação de materiais instrucionais adaptados às atividades de EF, fomentação de pesquisa na área de Educação Física Adaptada, entre outras providências. Corroborando com esta idéia, ${ }^{7}$ concluíram em sua pesquisa que para acontecer o processo de inclusão os professores necessitam de apoio do governo, no que se refere a oferecimento de cursos de reciclagem, auxílio técnico pedagógico especializado, estrutura adaptada do espaço físico e material didático adequado. Só assim o processo inclusivo na área da EF poderá ser acessível e contribuir para a construção de uma nova sociedade, através de transformações nos ambientes e na concepção humana no geral. ${ }^{12}$ 


\section{METODOLOGIA}

Este estudo consiste em um relato de experiência vivenciado por uma discente da disciplina Prática Pedagógica V, pertencente à Grade Curricular do Curso de Graduação em Educação Física da Universidade Federal de Viçosa - Campus Viçosa - no período de março de 2010 a julho de 2010.

Os discentes do sétimo semestre do Curso de Graduação em Educação Física que cursaram a disciplina Prática Pedagógica V atualmente residem em Viçosa, com faixa etária entre 19 a 29 anos e a média de alunos por semestre consta de 50.

No que se refere à sistematização do conteúdo transmitido aos discentes, o processo abrangeu, discussão sobre o ementário da disciplina, seus objetivos geral e específico. $\mathrm{O}$ objetivo geral de proporcionar uma reflexão sobre a atuação pedagógica do profissional de EF no espaço escolar, proveniente das observações e vivências dos conteúdos da Educação Física Adaptada I. Assim a disciplina Prática Pedagógica IV (P1), pretendeu discutir os conteúdos pertinentes a Educação Física Adaptada.

No primeiro momento a P1, houve a apresentação dos esportes adaptados de forma expositiva por parte do docente. Os conteúdos repassados aos dissentes, inicialmente pretendeu ratificar como se atingiu o processo de inclusão escolar, passando por conceitos de segregação à inclusão. Após a exposição deste tema, foram apresentados os assuntos para a produção dos seminários por parte dos discentes.

Vislumbramos que esse foi um momento primordial para que docentes e discentes começassem a construir uma relação de co-responsabilização pelas ações que seriam implementadas, uma vez que futuramente iremos entrar em contato direto com as necessidades da prática pedagógica em Educação Física Adaptada, no ambiente escolar.

Um segundo momento na P1, foi discutido, a organização e a exposição dos trabalhos referente ao conteúdo da disciplina Educação Física Adaptada I e Prática Pedagógica IV, sendo uma das sugestões a confecção de um trabalho escrito de caráter de revisão bibliográfica em conjunto a uma proposta de aula inclusiva vinculada ao ambiente escolar,

Conexões: revista da Faculdade de Educação Física da UNICAMP, Campinas, v. 10, n. 1, p. 142-152, jan./abr. 2012. 
cujo tema central era um determinado esporte paraolímpico (atletismo, basquetebol, bocha, ciclismo, esgrima, futebol de 5, futebol de 7, goalball, halterofilismo, hipismo, judô, natação, remo, rúgbi, tênis de mesa, tênis em cadeira de rodas, tiro com arco, tiro esportivo, vela e voleibol sentado). Para tanto, formamos grupos com a finalidade de elaborar o trabalho de revisão, sendo cada grupo com um esporte paraolímpico. Após a entrega deste trabalho, foram realizadas discussões sobre o mesmo entre a turma.

No momento da apresentação, os demais discentes participavam observando e analisando os possíveis aspectos que poderiam ser relevantes para a discussão que ocorria ao final da apresentação.

\section{RESULTADOS E DISCUSSÃO}

Durante as aulas expositivas ministradas na P1 pela professora da disciplina, pôde-se observar alguns pontos relevantes. A metodologia utilizada foi diferenciada das demais práticas pedagógicas, desenvolvidas com esta turma de EF ingressante no ano de 2007. No decorrer das aulas foi possível repensar a construção do conteúdo da Educação Física Adaptada no âmbito escolar. Isto foi viabilizado pelas aulas expositivas focada no tema Inclusão Escolar e posteriormente nos seminários desenvolvidos pelos próprios discentes com tema "Esporte Paraolímpico".

Os questionamentos levantados durante as aulas foram altamente relevantes para todos, pois podemos identificar as fragilidades da atuação do profissional de EF e do ensino atual. Neste aspecto, ainda percebermos a importância de unir os conhecimentos, ideias, comportamentos sociais, histórico e a prática em prol de uma finalidade, detectar os problemas reais e buscar soluções originais e criativas para inserção de indivíduos com deficiência, seja ela física, intelectual, sensorial ou múltipla.

Outros pontos abordados durante a disciplina foram discussões de textos sobre inclusão escolar, recortes de figuras das diferentes deficiências e possíveis atividades que poderia ser desenvolvidas, como também reflexões mediantes imagináveis adaptações durante uma aula de EF em função de alguma deficiência. 
Percebemos a possibilidade de trabalharmos o tema Esporte Paraolímpico na perspectiva sistematizada, ao mesmo tempo criativa e inclusiva no âmbito escolar. O desenvolvimento dos seminários valorizou o conhecimento já possuído pelos discentes, deixando claro o que cada grupo pensava sobre o esporte específico e sua aplicabilidade na escola de forma inclusiva, além do momento enriquecedor ao final de cada seminário, devido as discussões realizadas. Durante este momento foi possível debater a respeito do esporte paraolímpico e o plano de aula através das atividades apresentadas e suas aplicabilidades. Assim, possibilitou o desenvolvimento de uma consciência crítico-reflexiva com a finalidade de transformação do sujeito inserido no contexto social e político do momento em que vivemos em favor a uma Educação Inclusiva.

Assim, ficou evidente o quanto as aulas teórico-expositivas contribuíram para a nossa formação, mesmo com a forma diferenciada de repassar o conteúdo da prática pedagógica, estes foram consistente. Nesse sentido, percebemos que as construções do conhecer, refletir, agir e saber fazer a prática pedagógica em Educação Física Adaptada estão intimamente ligados. Estas ações devem ser trabalhadas continuamente, pois não são um fim em si mesmo, mas um processo em construção.

De acordo com as leituras e o conhecimento adquirido pela disciplina, podemos inferir que o processo de inclusão caminha vagarosamente. A EFI-437 Prática Pedagógica IV foi uma iniciativa de preparar e instigar os futuros profissionais de EF para a realidade escolar em que estamos inseridos, a era, da Educação Inclusiva. Como aponta o autor Gomes e Barbosa, ${ }^{13}$ no Brasil, um passo importante para assegurar o direito à educação sem exclusão para os PNEE (portadores de necessidades educacionais especiais) se deu com a promulgação da lei no 9394/96 - Nova Lei de Diretrizes e Bases Nacional (LDB) em 1996, na qual seu Artigo $4^{\circ}$ determina que: "atendimento educacional especializado gratuito aos educandos com necessidades especiais, preferencialmente na rede regular de ensino". ${ }^{19}$

No estudo de Morley et al. ${ }^{14}$ evidencia como a Inclusão é considerada por professores da EF. Os autores encaram como uma jornada, na qual a inclusão poderia ser um princípio alcançado se os recursos do processo inclusivo, como o apoio adequado, recursos e treinamento - fossem desenvolvidos de forma mais ampla, ou mesmo completamente 
mudada. Como já foi mencionado antes o governo precisa viabilizar fomento para que o processo se torne realidade de forma coerente com a teoria.

Nesse sentido percebemos a importância de construir um conhecimento a respeito do processo de inclusão e sua aplicabilidade no ambiente escolar, para tanto também temos que nos ater que não somente os professores tem o encargo de prosseguir com a inclusão. Esta é uma responsabilidade social, envolvendo órgãos administrativos escolares e governamentais, funcionários escolares, pais e irmãos, enfim a sociedade.

Portanto pensar em algo que fuja ao padrão de normalidade, socialmente construído, ainda será tema de muitos debates e discussões, e assim acreditamos na construção de uma verdadeira inclusão, e que esta não seja apenas algo utópico. Nas discussões em aula, percebemos o interesse de muitos dos discentes nessa área de atuação, alguns mudaram seu modo de pensar referente ao trabalho a ser desenvolvido com indivíduos com necessidades especiais. Porém outros, ainda agiram de forma irredutível, pensando a inclusão como algo impossível de realizar. O que nos leva a uma preocupação para com esta prática e a forma como ela será viabilizada posteriormente.

\section{CONCLUSÃO}

Este relato demonstra como o ensino superior de Graduação em EF na UFV, e em específico a disciplina de Prática Pedagógica em Educação Física Adaptada, está preparando seus discentes para uma possível realidade educacional. Isto permite a expansão de um modelo de preparação profissional, que, poderá induzir ao aprimoramento da formação acadêmica a área no Brasil. Também possibilitará uma preparação mais sólida, referente ao tema Educação Física Adaptada, de forma a buscar pela necessária competência profissional, melhorando a qualidade dos serviços prestados à sociedade.

Assim, através da realização de aulas expositivas, apresentação dos seminários, seguidas de discussão, os discentes tiveram a oportunidade de refletir como é necessário o domínio do conhecimento, o desenvolvimento de novas metodologias e técnicas, bem como a prática docente. 


\section{REFERÊNCIAS}

${ }^{1}$ CAMPBELL, S. I. Múltiplas faces da inclusão. Rio de Janeiro: Wak, 2009.

${ }^{2}$ MENDES, E. G. A radicalização do debate sobre inclusão escolar no Brasil. Revista Brasileira de Educação, v.11 n. 33, p. 387-405, set./dez. 2006.

${ }^{3}$ MARQUES, L. P. et al. Analisando as pesquisas em educação especial no Brasil. Revista Brasileira de Educação Especial, Marília, v.14, n. 2, p. 251-272, maio/ago. 2008.

${ }^{4}$ FERREIRA, M. E. C.; GUIMARÃES, M. Educação inclusiva. Rio de Janeiro: DP\&A, 2003.

${ }^{5}$ GLAT, R. A integração social dos portadores de deficiência: uma reflexão. Rio de Janeiro: Sette Letras, 1995.

${ }^{6}$ GLAT, R.; NOGUEIRA, M. L. de L. Políticas educacionais e a formação de professores para a educação inclusiva no Brasil. Revista Integração, Brasília, v. 24, n. 14, p. 22-27. 2002.

${ }^{7}$ SOUZA, M. A. Prática pedagógica: conceito, características e inquietações. In: ENCONTRO IBERO-AMERICANO DE COLETIVOS ESCOLARES E REDES DE PROFESSORES QUE FAZEM INVESTIGAÇÃO NA SUA ESCOLA, 4., Ponta Grossa, 2005. Anais... Disponível em:

<http://ensino.univates.br/ 4iberoamericano/trabalhos/trabalho024.pdf>. Acesso em: 20 abr. 2011.

${ }^{8}$ GATTI JÚNIOR, D. Modernidade, escolarização e sociedade de direitos: a questão do livro didático de história no Brasil (1988-2010). In: ENCONTRO NACIONAL DE DIDÁTICA E PRÁTICA DE ENSINO CONVERGÊNCIAS E TENSÕES NO CAMPO DA FORMAÇÃO E DO TRABALHO DOCENTE: POLÍTICAS E PRÁTICAS EDUCACIONAIS,15., Belo Horizonte, 2010. Anais... Belo Horizonte: Autêntica, 2010. p. 564-582.

Conexões: revista da Faculdade de Educação Física da UNICAMP, Campinas, v. 10, n. 1, p. 142-152, jan./abr. 2012. 
${ }^{9}$ NÉLISSE, C. La’intervention: les savoirs en action. São Paulo: edições GGC, 1997.

${ }^{10}$ SOARES, C. L. et al. Metodologia do ensino da Educação Física. São Paulo: Cortez, 1992.

${ }^{11}$ AGUIAR, J. S.; DUARTE, E. Educação inclusiva: um estudo na área da Educação Física. Revista Brasileira de Educação Especial, Marília, v.11, n.2, p.223-240, maio/ago. 2005.

12 SASSAKI, R. K. Inclusão: construindo uma sociedade para todos. 3. ed. Rio de Janeiro: WVA, 1999.

${ }^{13}$ GOMES, C.; BARBOSA, A. J. G. Inclusão escolar do portador de paralisia cerebral: atitudes de professores do ensino fundamental. Revista Brasileira de Educação Especial, Marília, v.12, n.1, p. 85-100, jan./abr. 2006. Disponível em: <http://www.scielo.br/scielo.php?script=sci_arttext\&pid=S1413-65382006000100007> Acesso em: 23 abr. 2011.

${ }^{14}$ MORLEY, D. et al. Educational Needs and/or disabilities in physical education inclusive physical education: teachers' views of including pupils with Special. European Physical Education Review, p. 84-107, 2005. 